\title{
Lanthanum oxide application for modifying the properties of chemically resistant ceramics produced with Galvanic Sludge additive
}

\author{
I.A. Vitkalova ${ }^{1}$, A.S. Uvarova ${ }^{2}$, E.S. Pikalov ${ }^{3}$, O.G. Selivanov ${ }^{4}$ \\ ${ }^{1}$ Vladimir State University named after A. G. and N. G. Stoletovs, Vladimir, Russian Federation \\ iavitkalova@gmail.com \\ ${ }^{2}$ Vladimir State University named after A. G. and N. G. Stoletovs, Vladimir, Russian Federation, \\ astorlova@mail.ru \\ ${ }^{3}$ Vladimir State University named after A. G. and N. G. Stoletovs, Vladimir, Russian Federation \\ evgeniy-pikalov@mail.ru \\ ${ }^{4}$ Vladimir State University named after A. G. and N. G. Stoletovs, Vladimir, Russian \\ Federation,selivanov6003@mail.ru
}

\begin{abstract}
This article highlights lanthanum oxide impact on the basic performance properties of the chemically resistant ceramics based on low-plasticity clay. Such clay application in ceramic industry is limited due to its low strength, high water absorption and cracking of the products made from it. Thus for the effective use of this clay, it is necessary to modify it using various additives. Additional functional additives introduced into the charge composition are boric acid and galvanic sludge, their combined application allows for ceramics liquid-phase sintering at the temperature of $1050^{\circ} \mathrm{C}$ to produce chemically and thermally resistant glassy phase, which serves as a binder among the crystal phase particles and provides the products self-glazing effect. The research results revealed that lanthanum oxide is a part of the vitreous phase, which increases its strength, chemical and thermal stability. It was found that lanthanum oxide introduction in the amount of $5 \mathrm{wt}$ \% allows for effective improvement of the main performance properties of the studied ceramics and the products quality.
\end{abstract}

Key words:chemically resistant ceramics, lowplasticity clay, lanthanum oxide, galvanic sludge, boric acid, self-glazing effect, environmental safety

\section{INTRODUCTION}

Chemical resistant products include acid-resistant and alkali-resistant ceramic items used for masonry and facing of foundations, floors, walls and building structures performing in contact with aggressive media, for the shaped products manufacturing, attachments and products for chemical equipment, for masonry and lining of devices, pipelines, chimneys and flues in chemical, metallurgical, petrochemical and dairy industries.

Chemically resistant ceramics is characterized by heat resistance, high mechanical strength, low water absorption, water and gas tightness alongside the resistance to aggressive media at both normal and elevated temperature. These properties are ensured by raw materials properties and firing at temperatures over $1200{ }^{\circ} \mathrm{C}$. An additional improvement of chemical and heat resistance, and water absorption decrease are provided by the glazing layer on the products surface for some types of chemically resistant ceramics $[1,2]$.

Chemically resistant ceramics include clinker ceramics, porcelain and semi porcelain, produced on the basis of high plasticity clays, and technical ceramics produced on the basis of high-melting and refractory clays, high-melting minerals (forsterite, spinel, etc.) or as a result of sintering oxides, carbides, nitrides, borides and silicides of metals such as aluminum, magnesium, yttrium, zirconium, titanium, etc. [3, 4].

The wide application of these raw materials is limited because of their high cost and limited natural reserves. Therefore, the development of charge compositions and methods for mass production of chemically resistant ceramics using wider spread and cheaper raw materials is an urgent task.

The authors have previously developed a charge composition based on low-plasticity clay, used for producing acid-resistant ceramics by introducing $5 \mathrm{wt}$. \% boric acid as flux, $5 \mathrm{wt}$. \% lanthanum oxide and up to $5 \mathrm{wt}$. $\%$ galvanic sludge. Boric acid was found to provide borosilicate amorphous phase formation characterized by acid resistance and heat resistance, but heavy metal oxides formed during firing from galvanic sludge, along with lanthanum oxide, further increase ceramics acid and heat resistance. The combined introduction of these additives facilitates the effects of surface self-glazing and in depth glazing [1]. The authors achieved self-glazing and glazing effects of ceramics in other works, thus increasing heat resistance, strength and frost resistance, and reducing water absorption of the products [5-8].

The research objective was to study the dependence of the performance properties of the developed material on lanthanum oxide content in the charge and the choice of the component amount providing high-quality chemically resistant ceramics.

\section{RESEARCH OBJECTS AND METHODS}

The main component for the developed ceramics bricks production was the clay from Suvorotskoye deposit in the Vladimir region of the following composition (wt.\%): $\mathrm{SiO}_{2}=67.5 ; \mathrm{Al}_{2} \mathrm{O}_{3}=10.75 ; \mathrm{Fe}_{2} \mathrm{O}_{3}=5.85 ; \mathrm{CaO}=2.8 ; \mathrm{MgO}=$ $1.7 ; \mathrm{K}_{2} \mathrm{O}=2.4 ; \mathrm{Na}_{2} \mathrm{O}=0.7$. The clay plasticity equals 5.2 
that is why in compliance with state standard GOST 916975 it refers low plasticity clay and the materials produced on its basis without any functional additives are characterized by poor strength, high water absorption and crack formation on the surface and in depth $[1,9]$.

For producing the liquid-phase sintering and selfglazing effect, boric acid of grade B of the 2nd grade, containing the main substance in an amount of at least 98.6 $\%$ wt. (GOST 18704-78), lanthanum oxide of Lao-D brand, containing main substance in an amount of at least 99.89577 wt. \% (TU 48-4-523-89) and electroplating sludge, received after the effluent chemical treatment at the electroplating enterprises of "Zavod" Avtopribor" PLC (Vladimir) were introduced into the charge.

The sludge composition included the following compounds (wt. \%): $\mathrm{Zn}(\mathrm{OH})_{2} \approx 11.3 \% ; \mathrm{SiO}_{2} \approx 7.08 \%$; $\mathrm{Ca}(\mathrm{OH})_{2} \approx 16.52 \% ; \mathrm{Cr}(\mathrm{OH})_{3} \approx 9.31 \% ;\left(\mathrm{Fe}^{2+}\right) \mathrm{Cr}_{2} \mathrm{~S}_{4} \approx 4.17 \%$; $\mathrm{CaCO}_{3} \approx 40.25 \% ; \mathrm{CaO} \approx 3.45 \% ; \mathrm{ZnO} \approx 2.41 \% ; \mathrm{Cu}(\mathrm{OH})_{2} \approx$ $2.38 \% ; \mathrm{Ni}(\mathrm{OH})_{2} \approx 2.62 \% ; \mathrm{Mn}(\mathrm{OH})_{2} \approx 0.64 \% ; \mathrm{Pb}(\mathrm{OH})_{2} \approx$ $0.14 \%[1,2]$.

Prior the application the clay and galvanic sludge were dried to a constant mass and crushed up to the particle size fraction of no more than $0.63 \mathrm{~mm}$. Afterwards all the charge components were mixed at the specified ratios first dry, and then with the addition of 8 wt. $\%$ of water producing the homogeneous mass, used for making the samples of chemically resistant ceramics under the pressing pressure of $15 \mathrm{MPa}$ and maximum firing temperature of $1050{ }^{\circ} \mathrm{C}$.

Acid resistance (AcR, \%), alkali resistance (AlR, \%), heat resistance (HR $\left(1000{ }^{\circ} \mathrm{C}\right.$ - water $)$, thermal shifts), open porosity $\left(\mathrm{P}_{\mathrm{op}}, \%\right)$, compressive strength $\left(\sigma_{\mathrm{cmp}}, \mathrm{MPa}\right)$ and bending strength ( $\left.\sigma_{\mathrm{bnd}}, \mathrm{MPa}\right)$, water absorption (WA, \%) and frost resistance (FR, cycles) were determined for the samples in compliance with the standard methods for ceramic materials.

\section{RESEARCH RESULTS AND DISCUSSION}

The previous experiments results stated that the introduction of boric acid over 5 wt. \% causes the vitreous phase excess and the loss of products shape. Besides the introduction of galvanic sludge over $5 \mathrm{wt}$. \% causes the strength decrease and water absorption increase as heavy metal hydroxides and calcium carbonate, being a part of galvanic sludge, decompose during ceramics firing with the formation of water vapor and carbon dioxide, which increase porosity [1, 2]. In this regard, the research experiments were carried out using the charge compositions, containing $5 \mathrm{wt}$. $\%$ of boric acid, $5 \mathrm{wt}$. $\%$ of galvanic sludge and up to $10 \mathrm{wt}$. \% lanthanum oxide.

The experiments results conducted during the research revealed that the acid and alkali resistance of the developed ceramics rises alongside the increase of lanthanum oxide amount in the charge (Fig. 1).

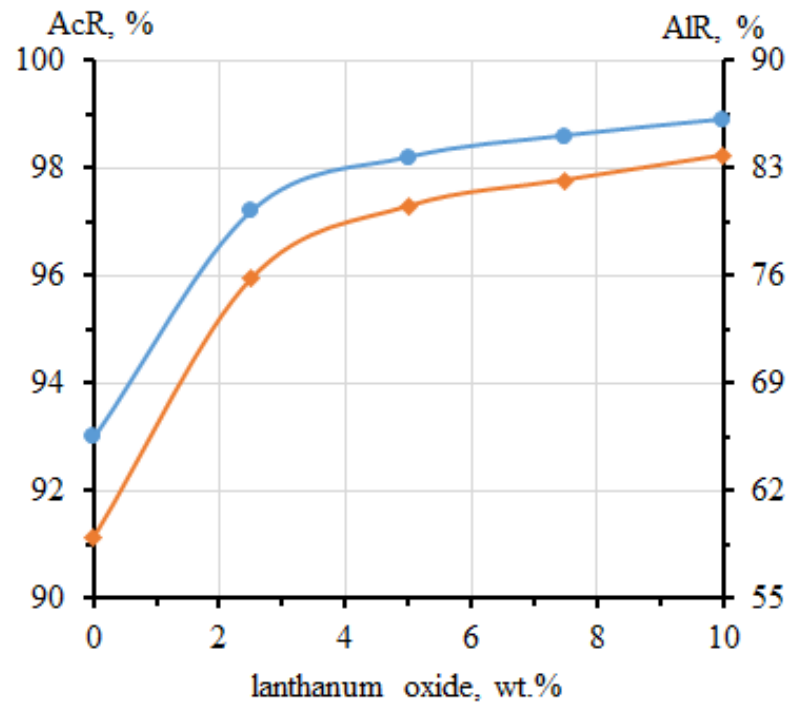

$\multimap-$ acid resistance $\multimap$ alkali resistance

Figure 1: Acid and alkali resistance dependence on lanthanum oxide content in the charge composition

The additive effect on these properties can be explained by the fact that the fluxing action of boric acid and calcium oxide, being a part of galvanic sludge and clay, contributes to the transition of some part of the lanthanum oxide into the vitreous phase, which creates self-glazing effect on the surface of the developed material and ceramic particles glazing in the sample depth. At the same time, lanthanum oxide is known to increase acid and alkali resistance of glass and ceramic [10-12].

The research results also revealed that lanthanum oxide amount increase in the charge increases temperature resistance and reduces open porosity ratio of the developed ceramics (Fig. 2).

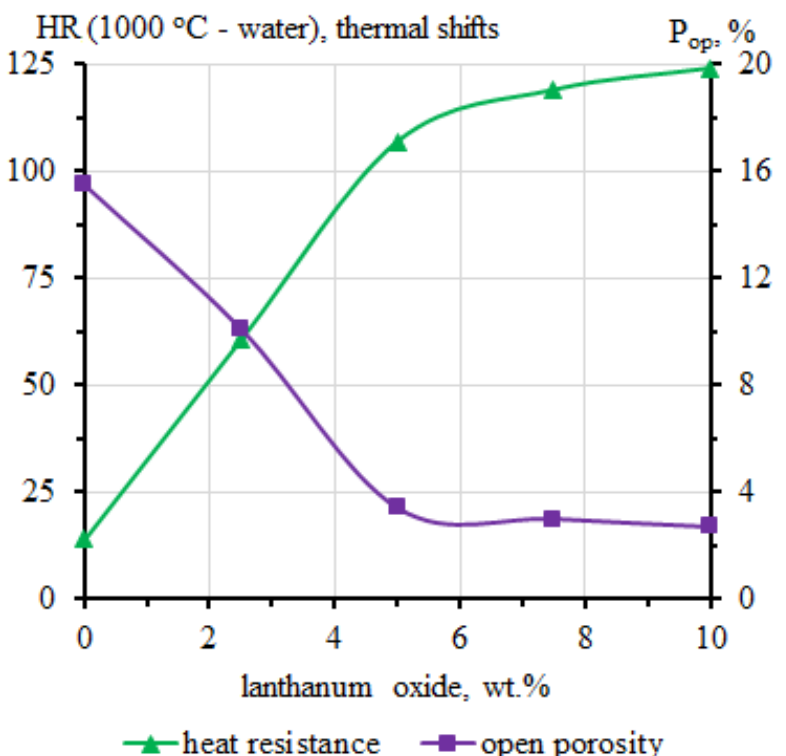

Figure 2: Heat resistance and open porosity dependence on lanthanum oxide content in the charge

The nature of the received dependencies is explained by the fact that lanthanum oxide in the vitreous phase increases its thermal stability [1], and by the fact that this oxide is one of the vitreous phase sources, and, consequently, one of the reasons for self-glazing effect, 
which transforms most of the open pores into the closed ones.

Lanthanum oxide participation in the vitreous phase formation and particles vitrification effect creation causes leads to the fact that vitreous phase serves as a binder between ceramic particles, forming the frame in the material, causing the increase of ceramics strength characteristics, which is proved by the experiment data results (Fig. 3).

The decline in the open pores ratio due to the selfglazing effect produced by lanthanum oxide participation causes water absorption decrease and, consequently, frost resistance improvement of the developed ceramics which is confirmed by the dependence of these properties on lanthanum oxide amount in the charge (Fig. 4).

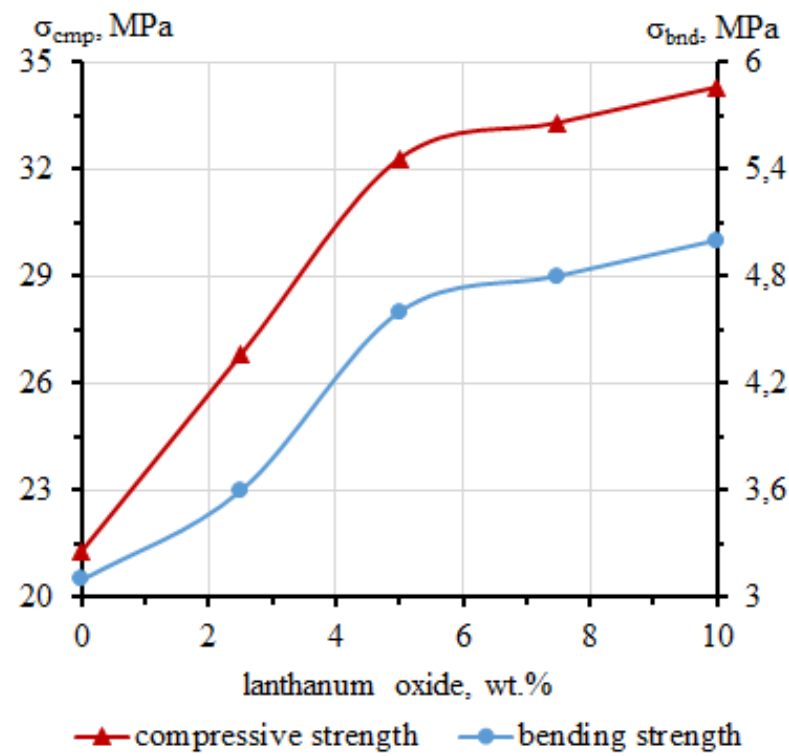

Figure 3: Compressive and bending strength dependence on lanthanum oxide content in the charge composition

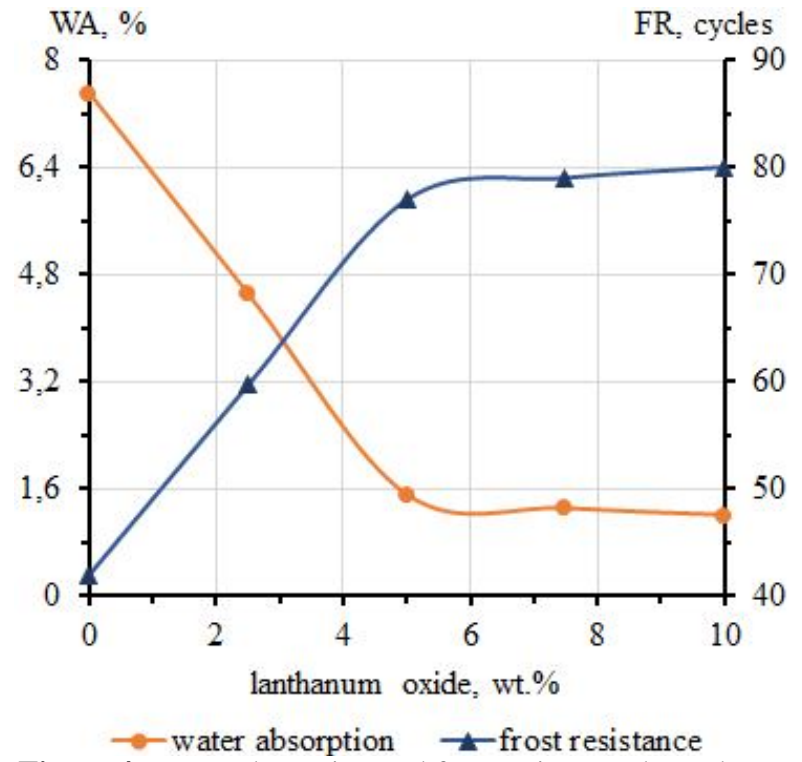

Figure 4: Water absorption and frost resistance dependence on lanthanum oxide content in the charge composition

Thus, lanthanum oxide introduction into the developed charge composition causes the increase of chemical resistance, strength and frost resistance while reducing open porosity and water absorption of the products. At the same time, the biggest increase of ceramics chemical resistance is observed at lanthanum oxide introduction of up to $2.5 \mathrm{wt}$. \%, and the biggest increase of heat resistance, strength and frost resistance is achieved by introducing of up to $5 \mathrm{wt}$. $\%$ of the studied additive. It should be noted that the introduction of more than $5 \mathrm{wt}$. \% of lanthanum oxide, the open pores ratio is practically stable, probably due to the fact that this amount of additive transfers all sufficiently large open pores into the closed ones, and the resulting fuse cannot penetrate into smaller pores due to insufficiently low viscosity. As a result, further increase of lanthanum oxide amount in the charge composition, water absorption and frost resistance practically do not change. In this regard and taking into account the fact that lanthanum oxide introduction increases the charge cost, it was decided to introduce $5 \mathrm{wt} \%$ of lanthanum oxide into the charge.

\section{CONCLUSIONS}

The experiments result revealed that 5 wt. $\%$ of lanthanum oxide introduction into the charge, based on low-plasticity clay, with the additional introduction of 5 wt. \% of boric acid and 5 wt. \% of galvanic sludge promotes the production of ceramic material possessing high acid resistance, alkali resistance, strength and frost resistance and low water absorption.

The developed charge composition makes it possible to use poor demand low plasticity clay in ceramic production and utilize galvanic sludge - waste which is hazardous for the environment and its processing is time and energy consuming issue.

The received values of main performance properties are mostly suitable for the application of the resulting ceramic material for the production of acid-resistant bricks and clinker tiles for masonry and facing walls and foundations of industrial buildings, as well as for lining chimneys and flues.

\section{REFERENCES}

1. I. Vitkalova, A. Torlova, E. Pikalov, O. Selivanov"Industrial waste utilization in the panels production for high buildings facade and socle facing." E3S Web of Conferences. 2018, Vol. 33, 02062.

2. I.A.Vitkalova, A.S. Torlova, E.S. Pikalov, O.G. Selivanov"The use of waste containing heavy metals to produce acid-resistant ceramics with the effect of selfglazing.'Ecology of industrial production. 2018, Vol. 102, Iss. 2, pp. 2-6.

3. T. Wu, J. Zhou, B. Wu " $\mathrm{HF} / \mathrm{HCl}$ acid resistance mechanisms of alumina ceramics in the $\mathrm{Al}_{2} \mathrm{O}_{3}$-MgOCaO-SiO ${ }_{2}-\mathbf{Y}_{2} \mathbf{O}_{3}$ system."Ceramics International. 2019, Vol. 45, Iss. 4, pp. 4455-4460.

4. T.A. Otitoju, P.U. Okoye, G. Chen, Y. Li, M.O. Okoye, S. Li "Advanced ceramic components: Materials, fabrication, and applications."Journal of Industrial and Engineering Chemistry. 2020, Vol. 85, pp. 34-65.

5. A. Torlova, I. Vitkalova, E. Pikalov, O. Selivanov"Development of facade facing ceramics with self-glazing effect and increased energy efficiency."Advances in Intelligent Systems and Computing. 2020, Vol. 1116, pp. 552-559. 
6. I.A. Vitkalova, A.S. Torlova, E.S. Pikalov, O.G. Selivanov'The use of polymer and glass waste to obtain a self-glazing facing ceramic.'Ecology and Industry of Russia. 2019. Vol. 23, Iss. 11, pp. 38-42.

7. V.N. Shakhova, A.V. Berezovskaya, E.S. Pikalov, O.G. Selivanov, É.P. Sysoev“Development of SelfGlazing Ceramic Facing Material Based on LowPlasticity Clay.'Glass and Ceramics. 2019, Vol. 76, Iss. 1-2, pp. 11-15.

8. Vitkalova, A. Torlova, E. Pikalov, O. Selivanov, "Energy efficiency improving of construction ceramics, applying polymer waste."Advances in Intelligent Systems and Computing. 2019, Vol. 983, pp. 786-794.

9. O.G. Selivanov, E.S. Pikalov, A.S. Kolosova“Ceramic material for fluoride and phosphate ions removal from natural water.'International Journal of Emerging Trends in Engineering Research. 2020, Vol. 8,Iss. 5, pp. 1732-1735.

10. L. Bois, M.J. Guittet, N. Barré, P. Trocellier, S. Guillopé, M. Gautier, P. Verdier, Y. Laurent, "Aqueous alteration of lanthanum alumino-silicate glasses."Journal of Non-Crystalline Solids. 2000, Vol. 276, Iss. 1-3, pp. 181-194.

11. H. Chen, B. Li, M. Zhao, X. Zhang, Y. Du, Y. Shi, J.S. McCloy, "Lanthanum modification of crystalline phases and residual glass in augite glass ceramics produced with industrial solid wastes."Journal of Non-Crystalline Solids. 2019, Vol. 524, 119638.

12. S.S. Sujith, S.L.A. Kumar, R.V. Mangalaraja, A.P. Mohamed, S. Ananthakumar, "Porous to dense $\mathrm{LaPO}_{4}$ sintered ceramics for advanced refractories." Ceramics International. Vol. 40, Iss. 9, Part B, pp. 1512115129. 